\title{
DEVELOPMENT OF AN EXPERT SYSTEM FOR LANDFILLING APPLICATIONS IN SRI LANKA
}

\author{
ASANGA MANAMPERI ${ }^{1}$, L.C. JAYAWARDHANA ${ }^{2}$, AJITH DE \\ ALWIS $^{3}$, SUMITH PILAPITIYA ${ }^{4}$ \\ ${ }_{1,2,3}$ Department of Chemical \& Process Engineering, University of Moratuwa, Sri Lanka \\ ${ }^{t}$ The World Bank (Colombo Office), DFCC Bldg., Galle Road, Colombo 03, Sri Lanka
}

\begin{abstract}
An expert system was developed to assist proper implementation of landfill technology in Sri Lanka. The knowledge base was acquired through text books, manuals, technical reports, research publications and domain experts. An object oriented expert system shell, ACQUIRE 2.1 was used as the building tool for the prototype development. BESTFill expert system contains several sub modules by which the user can obtain a comprehensive background of the domain. The output is expected to support effective integrated solid waste management.
\end{abstract}

Key words: Expert system, Landfilling, Decision support tool

\section{INTRODUCTION}

Solid waste management has long been a problem area for local authorities in Sri Lanka. Uncontrolled dumping and burning is being practiced at large scale due to lack of proper guidance and awareness. The solid waste practices after the recent Tsunami event demonstrates how bad these practices were (Draft Field REA Report-Sri Lanka Tsunami, 2005). The main reason attributable to this deficiency is the lack of expertise in the solid waste management domain. The aim of this research is to address one of the main areas of solid waste management, the landfilling technology, in order to cater to the need of expertise in this area, by providing an expert system called BESTFill. Currently there are two operating landfill sites in Sri Lanka, with minimum facilities for treatment of leachate and landfill gas. However there are hundreds of other potential sites (currently used for open 

ALWIS, SUMITH PILAPITIYA

However there are hundreds of other potential sites (currently used for open dumping) which could be converted to sanitary landfills. To guide the proper implementation of this technology, the need of expertise, in the form of a human expert or a written program such as an expert system is a crucial factor. However in Sri Lanka, the human experts are extremely scarce for landfill technology, and are restricted to the few universities in the country. In order to convey the expert knowledge to the operational level personnel, the most convenient and cost effective means is an expert system.

\subsection{Expert Systems}

Solid waste management area has been a target for the development of expert systems in many countries. Expert systems were developed for many different sub divisions of solid waste management such as waste minimization, recycling, optimal transportation, optimal land use, designing of landfilling, composting and biogas facilities etc.

SWIM (Wang et al., 1998) was developed to provide a structure for systems analysis of solid waste management problems at the municipal level. The SWIM model identifies the costs for collection and transportation of waste/ recyclables and adverse environmental impacts associated with these operations. Waste Plan (http://www.epa.gov/opptintr/acctg/rev/813.htm) is a commercial model that has been developed as a policy analysis tool. The model allows users to build integrated solid waste management plans. HMA (Helsinki Metropolitan Area) model (Tanskanen, 2000) is for integrated analysis of separation strategies and their effects on recovery rates, waste streams, costs and emissions of regional municipal solid waste management. ORWARE (Organic Waste Research) model (Sonesson, 1998, Sonneson, 2000) is a simulation model for organic waste management systems. The objective is to facilitate studies of waste management systems. MSW-Xpert (Mc. Cauley-Bell and Reinhart,1997) was developed to assist in the planning and analysis phases of a waste composition study and to produce consistent results from country to coutry by controlling the variance in planning techniques. However this system has been developed only for users who are experienced in development of waste composition studies.

Leachate Management Advisor (LMA) (Basri, 2000), Landfill Design Advisor (LDA) (Basri \& Stentiford,1994), Landfill Restoration Plan Advisor (LRPA) (Basri,1998) and Visual Help (www.scisoftware.com/products/ visual_help_demo.html) have been designed to address different areas of landfilling applications. 
Compost Design Consultant (CDC) (Basri,1999) was developed to aid the preliminary design of composting facilities in treating municipal solid waste for developing countries.

The knowledge based system called ENVOP Expert (Environmental Optimization) has been first used to identify possible waste minimization alternatives and later extended for waste minimization analysis in chemical processes (Halim and Srinivasan, 2002).

These systems have proved their reliability and usefulness in their respective domains throughout the world. Therefore as a developing country, Sri Lanka too can benefit from the developed expert system for landfilling applications.

Among the many advantages of the expert systems, it could be highlighted for a country like Sri Lanka, that its ability to provide training facility for the key personnel in the solid waste management hierarchy. This can be easiliy achieved since expert systems contain the necessary knowledge and the ability to explain their reasoning process (Waterman,1986). By incorporating user-friendly interfaces and knowledge about teaching methods and user modeling, a smooth learning and training process between the trainee and the expert system could be achieved. As a training device the expert system provides new staff members with a vast reservoir of experience and strategies from which to learn about recommended policies and methods. The system can also be adapted to train novices in specific tasks such as, site selection, site preparation, leachate management, surface water management, usage of landfill machinery accepting and control of incoming waste, handling unusual wastes, record keeping, financial planning and so on. The experience from the two operating landfill sites shows that this type of training is a crucial factor for the better management of the sites. Since the planners and designers have been unable to convey their design and operational goals to the site managers and workers, the expected quality is hardly achieved. Expert systems can be used to bridge this knowledge gap, thus improving the quality of the project, dramatically.

The nature of the domain of landfilling technology provides many reasons for its suitability for the development of an expert system. There are no hard and fast solutions for most of the issues arising in this area. The knowledge base consists of the experience gathered through many human years of study or practice through trial and error. Therefore approximate 
methods, heuristics and rules-of-thumb makes up the entire knowledge base, except for a few exceptions. An expert system could be the only way to tackle a domain such as landfilling with so many ill defined concepts, over abundance of possibilities, difficulty of gathering information, uncertainty and unreliability of data, cost of gathering information and so many inconsistencies.

The domain of landfilling is essentially multi disciplinary in nature. It requires substantial contributions from geologists, engineers, biologists, economists etc. When the expert is in the form of an expert system, it would be much easier to gather information from various disciplines and incorporate into a one body. Problem solving becomes much easier when the system posses information from various disciplines involved with the issue.

Transferability (or reproducibility) of expertise is an essential factor when considering the substantial time, effort and cost involved in building up an expertise. Unlike transferring the human expertise, which is a lengthy, laborious and expensive process, the transferring of artificial expertise is a trivial process of copying or cloning programs or data files. The importance of this feature is highlighted when similar expertise is required at different locations. According to this scenario, when considering the hundreds of potential landfill sites and thousands of potential users, the developed expert system would be a very useful tool for the local authorities in Sri Lanka which numbers to 297.

\section{METHODOLOGY}

\subsection{Knowledge Acquisition}

Knowledge acquisition is the lengthiest process in building of an expert system. However it is the single most important process of the knowledge engineer upon which the quality of the expert system depend on. The central core of the knowledge base was acquired from the published text books and manuals. This knowledge consists of well established facts, rules, theory and guidelines that had been practiced over many years. Technical reports such as Environmental Impact Assessment reports, Initial Environmental Examination reports related to proposed, operated and abandoned landfill projects in Sri Lanka, have provided very valuable sources of information on applicability and suitability of landfill technology for Sri Lanka. This source 
of information provided a means to build a unique knowledge base for BESTFill expert system.

Domain experts provided the valuable source of expertise related to problem areas of landfill technology in Sri Lanka. Since most landfills in Sri Lanka have failed, abandoned or poorly operated, it could be traced from these human experts the deficiencies involved in these projects and what really went wrong. Also human expertise was helpful in organization and refinement of the knowledge base of the expert system, acquired from other sources. Most of the experts, however, were concentrated around the universities in the country, rather than involved with actual projects.

Knowledge acquisition has now become relatively easy than two decades ago, due to the advancement of Internet facilities. Much valued information about landfill operating procedures, organizations, experts and so on, were acquired through the Internet. These were helpful in building the sub modules of the BESTFill expert system.

\subsection{Building tool}

For the development of BESTFill,an expert system shell, ACQUIRE 2.1 (www.aiinc.ca), was preferred over conventional programming languages. Expert system shells are high level programming tools which has a built in inference engine. This feature improves productivity since the knowledge engineer needs only to add the knowledge base. ACQUIRE was preferred because of its object oriented approach which combines the two main knowledge representation techniques for expert systems, i.e. production rules for inferential knowledge, and objects (or frames) for static knowledge. ACQUIRE was selected because of its proven reliability and availability of its support facilities and documentation.

\subsection{User interface}

Proper organization of the user interface is important since it is the part of the expert system that interacts with the user. The presence of a standard user interface framework not only simplifies development efforts, but also reduces user training and support requirements for users (Grove,2000). In the BESTFill expert system, the knowledge base was divided into four categories as site, technology, safety and post closure, as shown in the figurel. Once the user type a keyword related to the desired area and activate the system, the system will display an entire list of questions related to that 
area. If the user finds it superfluous, he has the option to add on more keywords in order to narrow down the problem area. If the system requires more specifications or clarifications, it will prompt the user to input more data, instead of producing the answer in a one frame. The user can select the option "unknown" or give an approximate answer, if he is uncertain about an issue. Then the system may either ask for other inputs relevant to the issue, or else it will formulate the answer based on given data indicating all the uncertainties and assumptions. If the question is straight forward, the system will produce the answer through texts, charts or tables within a single frame. If the user wants additional information on landfilling, he can select one of the eight sub modules as shown in the figure 1.

\section{$2.4 \quad$ Inference engine}

Inference engine contains the general problem solving knowledge. It processes the domain'knowledge (located in knowledge base) to reach new conclusions. The inference engine acts upon the rules and other data related to landfilling to solve the problem and applies the rules as encapsulated in the knowledge base and draw inferences and records conclusions in the database (Beerel, 1993). The production rules were applied for the site related questions (site selection etc.) and objects or frames were used for other divisions, namely technology, safety and postclosure.

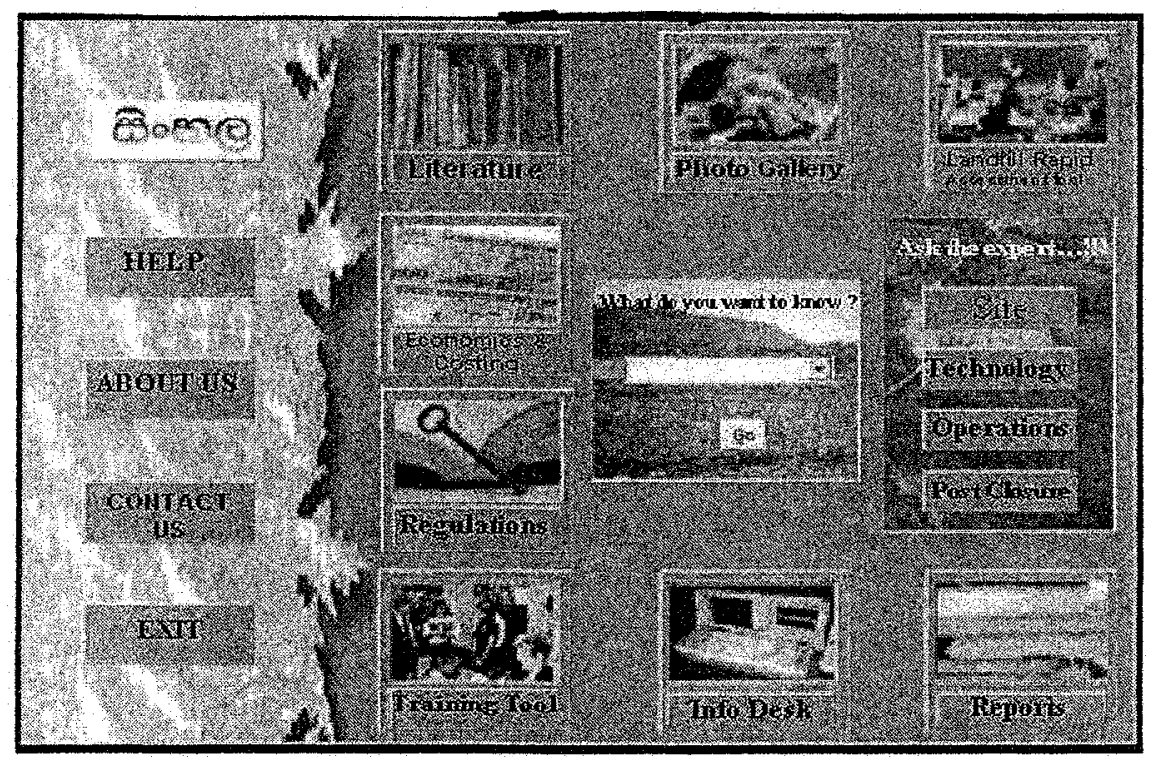

Figure1. Main user interface of BESTFill expert system 


\section{$2.5 \quad$ Sub modules}

A unique feature of BESTFill expert system is that it contains several submodules by which the user can obtain a comprehensive background understanding. The submodules were named as literature, info desk, training tool, photo gallery, landfill rapid assessment tool, economics \& costing, regulations and reports as shown in the figure 1.

The literature module consists of information about the relevant books, journals, research papers and websites (figure 2).

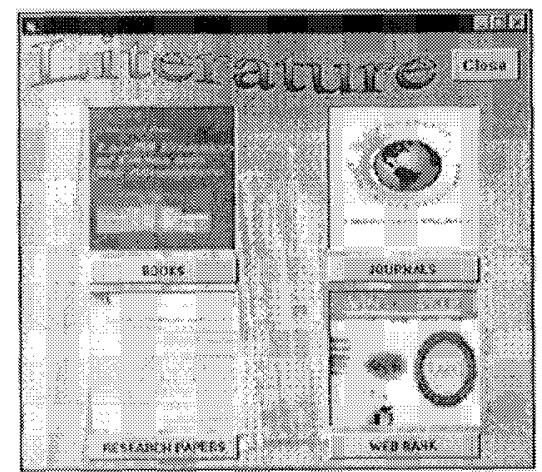

Figure2: Literature module

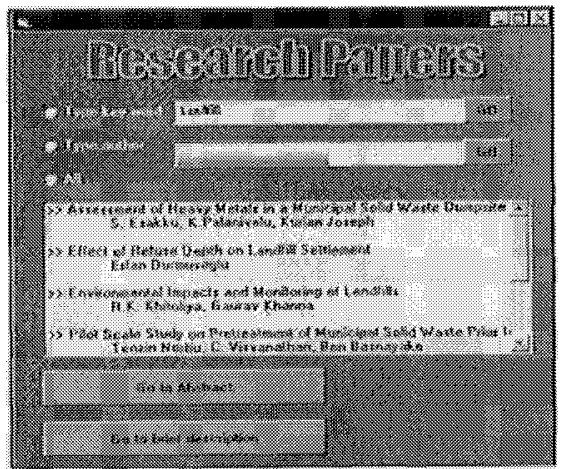

Figure3. Interface for Research Papers module

Books were categorized by the title and given with the information of authors, publishers, year, ISBN and a brief description. Similarly the journals were classified by the name and provided with the information such as publisher, address and a description. Relevant websites were downloaded and made accessible to the user, off line, and displayed in a screen similar to a search engine. Research papers related to landfilling were listed as shown in figure 3 and provided with the abstract and a brief summary.

Info desk is a module from which the user can obtain contact details of all the relevant experts, institutions and organizations involved in landfill applications (figure 4). Information of experts were given in the form of name, institution, country, address, email, telephone and personnel website (figure 5). The details of institutions and organizations were provided with similar interfaces with similar information. 


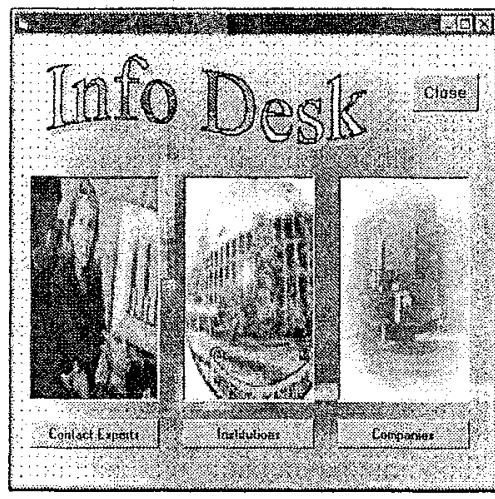

Figure 4: Info Desk module

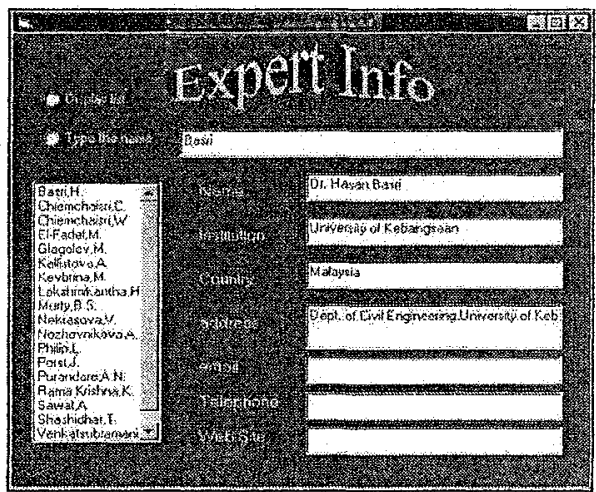

Figure 5: Interface for Expert Info

Landfill rapid assessment tool is embedded with technical details such as terminology, calculations and examples (Figure 6). If the user come across an unfamiliar term, he can go to the terminology section of the landfill rapid assessment tool module and type the word as shown in the figure 7. In the "calculations" module, the user can simply input the values for the variables and get the answer for all the calculations associated with landfill processes, in no time. Examples module is a further extension of the calculations module and also provided with a detailed example with all the relevant maps, tables, charts etc.

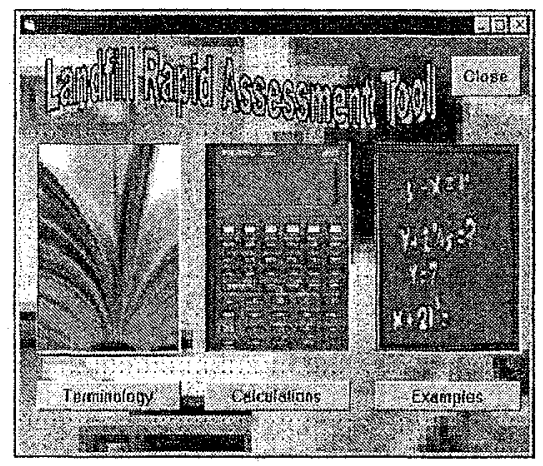

Figure 6: Landfill Rapid Assessment Tool Module

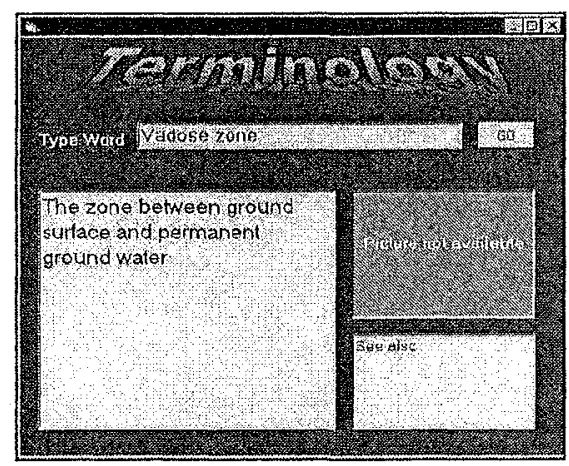

Figure 7: Interface for Terminology

Training tool module has been designed for the use of the novices to the field (Figure 8). It has been provided with six power point presentations highlighting the adverse effects of open dumping, adverse effects of 
improper planning of a landfill, necessary items of a landfill, benefits of a properly managed landfill, Hazardous waste secure landfills and an example of a well run and managed system of a developed country.

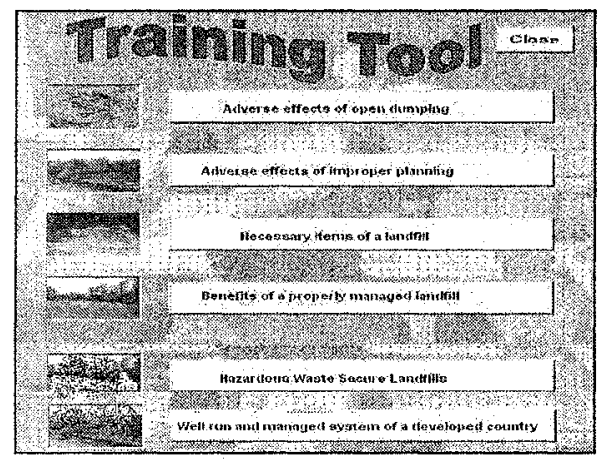

Figure 8: Training Tool module

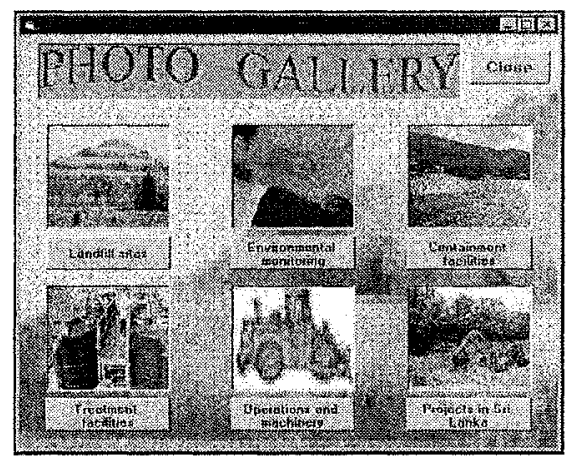

Figure 9: Photo Gallery module

Photo gallery consists of a huge collection of pictures and was divided into six areas as landfill sites, containment facilities, treatment facilities, environmental monitoring, operations and machinery and a separate collection of pictures of projects in Sri Lanka (Figure 9). Pictures were displayed as thumbnails and once selected, were provided with full picture and a brief description.

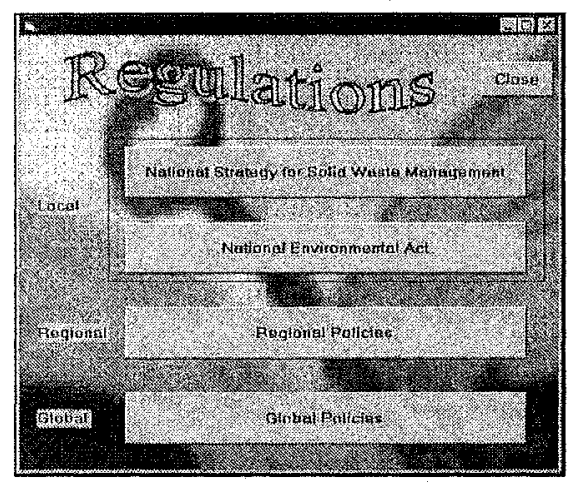

Figure 10: Regulations module

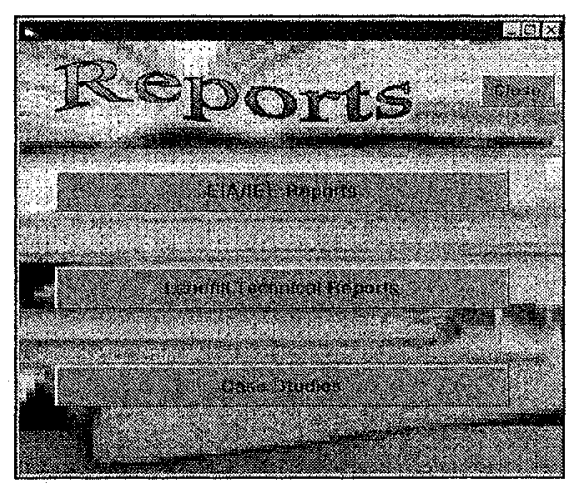

Figure 11: Reports module

Regulations module was incorporated in order for the user to obtain a background knowledge on legal framework associated with solid waste 
management. Regulations module was subdivided into local (legislation relevant to Sri Lanka), regional ( environmental policies pertaining to each South Asian country) and international (other important international policies)(Figure 10). Specific landfill directives such as of European Union are also included.

Reports module provides the user with Environmental Impact Assessment reports, Initial Environmental Examination reports, technical reports on landfilling and case studies carried out in landfill sites (Figure11).

\section{CONCLUSION}

The BESTFill expert system has been developed to cater to the need of expertise in landfill technology. The development has been carried out in several phases, including problem identification, knowledge acquisition, knowledge representation, programming, testing and validation. It has incorporated several user interfaces in order to make the system user friendly as much as possible. Among the potential users are local authorities, consulting firms, constructors, researchers and students. The output is expected to support effective integrated solid waste management.

\section{ACKNOWLEDGEMENT}

The funding provided by the University of Moratuwa, National Science Foundation for this research, continuing support and facilities provided by the Department of Chemical \& Process Engineering, University of Moratuwa to carry out this research are gratefully acknowledged.

\section{REFERENCES}

[1] ACQUIRE 2.1 ActiveX Control, Programmer's Guide, Acquired Intelligence Inc., \#205-1095 McKenzie Ave., Victoria, BC, Canada.

[2] Basri, H.B., An Expert System for Landfill Leachate Management, Environmental Technology, 2000, 21: 157-166.

[3] Basri, H.B., Stentiford, E.I., Expert Systems in Solid Waste Management, Waste Management \& Research, 1994, 13: 67-89.

[4] Basri, H.B., (1998), An Expert System for Planning Landfill Restoration, Wat. Sci. Tech., 1998, vol.37,No. 8: 211-217. 
[5] Basri, N.E.A, Stentiford, E.I., Basri, H., Development of an expert system for the design of composting facilities for municipal solid waste, Proceedings World Engineering Congress (Civil Engineering) 1999 (24-26 November), Kuala Lumpur, ISBN 967-960086-6, 1999: 13-20

[6] Beerel, A, Expert Systems in Business ( Real World Applications), Ellis Harwood Limited, 1993: 245-248.

[7] Draft Field REA Report-Sri Lanka Tsunami , Draft Field Report: Rapid Environmental Impact Assessment- Sri Lanka Tsunami, 2005.

[8] Grove R., Internet-based Expert Systems, Expert Systems, 2000, 17(3), 129-135.

[9] Halim, I., Srinivasan, R., Integrated Decision Support System for Waste Minimization Analysis in Chemical Processes, Environ. Sci. Technol., 2002, 36, 1640 - 1648.

[10] McCauley-Bell P., Reinhart D., Development of a Waste Composition Study Planning and Analysis Tool - MSW_Xpert, Florida Center for Solid and Hazardous Waste Management, 1997, Report \# 97-3.

[11] Sonneson U., Calculating Transport Labour for Organic Waste from Urban to Rural Areas, Resources, Conversation and Recycling, 1998, 24 a: 335-348

[12] Sonneson U., Modeling of Waste Collection- A General Approach to Calculate Fuel Consumption and Time, Waste Management and Research, 2000,b: 115-123.

[13] Tanskanen J.H., An approach for Evaluating the Effects of Source Separation on Municipal Solid Waste Management, Helsinki University of Technology, Doctoral Thesis, Helsinki, 2000.

[14] Wang F.S., Richardson A.J., Roddick F.A., SWIM-Modeling Approach and its Applications, System Engineering Models for Waste Management, International Workshop in Gothenburg, Sweden, 1998.

[15] Waterman, D.A., A Guide to Expert Systems, Addison Wesley Longman ,Inc., New York, 1986.

[16] www.aiinc.ca

[17] www.scisoftware.com/products/visual_help_demo.html

[18] http://www.epa.gov/opptintr/acctg/rev/8-13.htm 